\title{
Predict Life Satisfaction Based on the Positive - Oriented Psychology Structure between Students of Islamic Azad University of Tehran: A Structural Equation Model
}

\author{
Maryam Dadjou \\ Department of General psychology, Science and Research Branch, \\ Islamic Azad University, Guilan, Iran \\ Bahman Akbari \\ Department of Psychology, Rasht Branch, \\ Islamic Azad University, Rasht, Iran
}

\section{Doi:10.5901/mjss.2014.v5n20p3070}

\begin{abstract}
The aim of this study is to predict life satisfaction based on the positive -oriented psychology structure between students of Islamic Azad University of Tehran. Researcher selected a sample size of 348 using Cochran formula, and he selected these individuals based on cluster sampling from 5 branches of Azad University in Tehran. The questionnaire used on self steam variable was Rosenberg's standard questionnaire (1969). The questionnaire used for spirituality and spiritual well-being was Palatino and Ellison questionnaire (1982), and Diner's and et al SLWLS was implemented for life satisfaction (1985). Hope variable questionnaire related to Schneider et al (1991) and religiosity variable of Golzari (2001) were selected. According to tests conducted in the Lisrel software and their results it was found that in the confidence interval equal with 95\%, hope (0.84) and self-steam (0.73)variables have positive and significant relationship with life satisfaction. Meanwhile, what made these students more satisfied was their hopefulness (comparing to self-steam). Also, both hope and self- steam variables play the role of mediator variable in relation to spirituality and satisfaction which the role of hopefulness was stronger than self-steam. Regarding to religiosity variable this is similar to spirituality variable too. However, regarding to social- economic situation, self steam variable has a higher position than hope variable.
\end{abstract}

Keywords: life satisfaction, self-steam, spirituality, spiritual well-being, hopefulness

\section{Introduction}

The main aim of common philosophy of human life - even utilitarian moral philosophy is happiness and satisfaction in life. With the emergence of the new science of positive psychology, in recent years considerable efforts to clarify the concepts of happiness, life satisfaction, subjective well-being and the psychological occurred. Related researches to these areas have prominent role in contemporary psychology. This shows the efforts of psychologists to evaluate this issue. Life satisfaction considered as a person's overall evaluation of his life, a key aspect of understanding the important components of subjective well-being and quality of life (Hobner et al, 2005). Researchers represented a provocative frameworks of evidence related to correlates and life satisfaction predictors, including demographic factors, personality traits, goals, values, attributes, relationships, life events, circumstances and cultures have come up with (Reyan and Dessy, 2001 , Dainer et al, 2003; Lent, 2004 ). Recent psychologists' efforts and researchers are to investigate and identify the factors affecting the well-being and optimal development. Meta-analysis showed that the external factors and demographic variables against internal resources and related psychological personalityare not powerful predictor mental in mental well-being and life satisfaction.Results demonstrate that personal and subjective factors are the strongest predictors of mental well-being. Since the majority of researchers in the last decades define external factors to explain life satisfaction the concept of subjective well-being, and the strongest predictors still remains unclear. In other word, the individual subjective experience is an important aspect of mental health, even the subjective experience resulting from perceptual positive errors. One of these factors is the subject of spirituality and religion. Spirituality and religion as factors influencing life satisfaction is a mental event, private and internal. Research suggests that religion and spirituality in many studiesare related and interact with well-being and life satisfaction (McFadden, 1995). Part of the positive psychology 
movement is to survey contrastive skills basedon power. In the past decade, spirituality, religion and religious coping have been considered as effective strategies to deal with the confusion and distress of many psychologists and counselors. Religious people have reported higher levels of happiness and satisfaction with life (Pulma and Pendelton, 1990). The subjects who earn higher scores on spirituality also getting higher scores on health-related personality traits and self-actualization (Telvezinsky et al, 1997). These results indicate that spiritual welfare may be effective as problemsolving and strategic direction, and this issue increases your mental and social welfare of life.Results suggest that life spiritual well-being filled with certainty in relation to God and included a religious, social, and psychological combination .

Palutezian and Alison (1982), in addition to define the spiritual welfare as personal satisfaction, a relationship with superior added a sensory of life targeting, since human beings can act as an integrated world these two dimensionsoverlap in establishing a sense of satisfaction. Spiritual welfare causes the person to have a unified identity, satisfaction, happiness, love, respect, positive view points, inner peace, purpose and direction in life. Several studies support the hypothesis that spiritual well-being can enhance mental function and adaptation. The researchers found that between intrinsic religious orientation and life satisfaction there is meaningful relationship. Clark and Lelkez (2005) also mentioned religion and spirituality as important determinants of life satisfaction.

Two other different structures whichhave received significant attention in the prediction of life satisfaction consist of hope and self-esteem. Self-esteem and hope have negative correlation with psychopathology indexes. Hope, selfesteem, predicate physical and mental health as it is with various indices including the self-reporting of health, subjective well-being, life satisfaction, effective coping and health promoting behaviors which have been identified (Shierer\& Carver, 2002). Other studies have shown that self-esteem (Zheng et al, 2004, Zhang, 2005; Kdama, 2005) is a strong predictor of life satisfaction.

Shogrin et al (2006) has done a study titled the role of positive psychology structurein adolescents' life satisfaction with and without cognitive disabilities. The results showed that hope, optimism, is the source of control \& self-following have significantly correlated also hope and optimism were strong predictors in life satisfaction. The final structural model of this study is presented below .

Zulig and colleagues (2006) examined the relationship between spirituality, religiousness and life satisfaction among college students in this study the perceived health play the intervening or mediating variable roll. The results showed that the model of spirituality and life satisfaction through self-perceived health is quite fitted. Religiosity and life satisfaction model also was relatively good through self-perceived health. Both models were similar in men and women. Students who attained higher scores in spirituality and religiosity also scored higher on perceived health, and this had an impact on life satisfaction .

French \& Joseph(1999) has done a research aboutreligiosityand happiness relationship in life.The results showed that between religiosity, purpose in life and happiness, there is a significant positive relation and the relation between happiness and purpose in life, is influenced by the target function in life .

Ayyash-Abdo\&Alamuddin(2007) in a research examined the predictors of subjective well-being of Lebanese student. In this study, the role of personality factors, self-esteem, optimism, and positive affect were examined in relation to subjective well-being. The results showed that students' subjective well-being, self-esteem, optimism, and positive affect are positively correlated. The results showed that the internal structures of personality in relation to demographic variables are better predictors of life satisfaction .

The results of Zang\&leung (2012)research about mediation effects of sex and age on relationship between selfesteem and lifesatisfactionshowed that the collective self-esteem relationship with a life satisfaction in men compared to women was stronger. The effect of individual self-esteem on specific domains of life was stronger in men than in women. The effect of individual self-esteem on satisfaction of lifespecific domains in older adults compared with young was stronger. The effect of collective self-esteem onlife satisfaction formspecific domains of lifewas stronger in younger people compared to older people .

Ullman \&TarTar(2011) in its research realized that there is a meaningful relationship between self esteem and life satisfaction ,immigrant adolescents in comparison with non-immigrant report low levels of satisfaction, between age and dignity significant difference didn't observe, younger people reported a better life .

Bailey et al (2007) were evaluated the relationship of hope, optimism and satisfaction in two studies. Results showed that there was a significant positive relation between optimism and hope with life satisfaction and in both studies, targeted thinkingfactor wasbetter predicting of life satisfaction.

Ciarrocchi\&Deneke(2006) has done a study titled hope, optimism / pessimism and spirituality as predictors of wellbeing, and therefore concluded that there is a significant relationship between these variables and spirituality, optimism and hope are strong predictors of well-being . 
Hoyman et al (2007) has done a study based on spirituality among newcomer students and its relationship with self-esteem, Body Image and stress. Results show that there is a significant relationship between spirituality and selfesteem. Although a negative relationship was found between self-esteem and stress, but spirituality in this relationship is a bumper. There was no significant difference between men and women in terms of spirituality .

Kamya (2000) in its research on students realized that between self-esteem and spiritual welfare, there is a positive significant relationship in other words people have high levels of spiritual welfare report higher self-esteem.Also, between spiritual well-being withneuroticism psychology there is a significant relationship. Results showed that spiritual well-being is a strong predictor of self-esteem (quoted in Hoyman, 2007) .

Kowsari findings (2008) about the relationship between religiosity and life satisfaction among scholars of religious sciences and psychology students showed that there is a significant positive relationship between religiosity and life satisfaction. Significant positive correlation was found between gender and satisfaction such that higher levels of life satisfaction in women than men. Between religiosity and gender significant positive relation wasn't found. It also became apparent that religiosity among clergy mans was more than academics. Significant positive relation was found between marital status and life satisfaction .

The results of Kaydgapand Salehi (2007) under the role of religion in the sense of happiness of students showed that students with high levels of religiosity are happier, also between some components of religiosity and some components of happiness there is a positive relation. One of the findings of this study was a significant difference between boys and girls student happiness that this difference in all of the components are in favor of girls it means the girls have higher happiness .

Soltanizadeh. et al (2007) in his study of predictors of life satisfaction based on religious attitude, mental health and individualvariables found that among variables the rate of depression of $19 \%$, the religious outlook of $7 / 2$ percent, the physical disease $3 / 8$ percent, socio - economic status $3 / 7 \%$ and totally these four variables $33 / 6 \%$ of variance significantly predict life satisfaction .

Thus, this studyis going to find out how isthe relationship of religiosity ,divinity, spirituality, life with self-esteem variables and how much is the potion of each positive psychology-oriented structures in the prediction of life satisfaction?

The main hypothesis of this study

- hope has significant relations with Life satisfaction .

- There is a significant relationship between self-esteem and life satisfaction .

Secondary research hypotheses

- According to the mediating role of hope, spirituality and life satisfaction has significant relations .

- According to the mediating role of hope, religiosity and life satisfaction has significant relations..

- According to the mediating role of hope, socio-economic status and life satisfaction has significant relations.

- According to the mediating role of self-esteem, spirituality and life satisfaction has significant relations.

- According to the mediating role of self-esteem, religiosity and life satisfaction has significant relations.

- According to the mediating role of self-esteem, socio-economic status has a significant relationship with life satisfaction.

Methods: This study was non-experimental research and correlation research statistical populations are all of Azad university students in Tehran. The sample consisted of 380 students who were selected for sampling methods.

Tools for this study consist of :

- Self-esteem: The 10-item measures of overall self-esteem Rosenberg (1969) will be used. This questionnaire has acceptable reliability and validity. Lorenzo- Hernandez and Ulet (1998) reported $77 / 0$ Cronbach alpha coefficient for the Spanish version. Mohammadi (1384) coefficient of reliability with Cronbach's alphamethods, retest and split-half has reported respectively the 0/69,0/78 and 0/68. Girin Berger et al (2003) with various ways examined validity and consistency of structures. Internal consistency of this scale has been reported to 0/88. Rosenberg scale correlated with the scale self-esteem Eysenck is equal to 0/63.

- Spirituality: in this study spirituality is a grade that the tester obtained from Paloteziyan and Ellison (1982)spiritual well-being. This test has 20 questions and is two subscales. Individual questions was related to the petty-scale of religious welfare and evaluatethe amount of a person's experience of satisfying relationship with God and questions of the couple's related to the welfare petty-scale that evaluate the sense of satisfaction of life. Paloteziyan and Ellison (1982) Cronbach's alpha reliability coefficients of spiritual wellbeing and existence and overall scale respectively 0/91, 0/91 and 0/93and Dehshiri et al (2007) respectively reported equal to 0/900/82 0/87. Results indicate confirmatory factor analysis of the scale validity.

- Life satisfaction: in this study satisfaction of living is a grade that tester obtained from 5-item scale of life 
satisfaction (SWLS) Dainer et al (1985).Reliability coefficient of the instrument through Cronbach's alpha is equal to 0/87 and test-retest coefficient was 0/79 (according to the Carr, 2004). This tool has been implemented in Iranand validity and reliability have been reported acceptable.

- Hope: Adult Hope Scale is a self-report questionnaire consisting of 12 items which is made by Schneider et al (1991) and its psychometric properties-has been approved. Cronbach's alpha coefficient for this scale is acceptable (for total hope is equal to 0/86, for the purpose of making the circuit 0/82and strategies 0/84). During the 10-week test-retest reliability was obtained 82/0 (Schneider, 2000). many researchessupport the reliability and validity of the questionnaire as a scale of hopefulness measure (Bryant and Vengrus, 2004). This questionnaire used in the sample of 100 men and its validity and reliability have been reported acceptable (Sweet M. and Mir Jafari, 1385; Alaeddin al, 2007).

- Religiosity: the purpose ofreligiosity in this study is the grade obtained by the person to practice of religious beliefs (Temple) (Golzari, 2001). This test consists of 25 questions that measure the practice of religious beliefs. Materials tested in four areas of doing the essential, performing the desirable, religious activities (membership in religious groups, etc.) and consider religion in making decisions and choices in life. Exam questions selected with regard to common religious behavior of pious Muslim youths. Each question has five options that can be scaled from zero to four. Thus, the lowest score of zero, meaning the failure of any religious beliefs and the highest score 100 represent practice of all religious beliefs.

- Economic situation: this variable also contributed to a couple of questions about a person's attitude in terms of overall economic conditions, compare the person with what groups in terms of economic impact, the extent of effect of financial tools in life and the role of economic and finance issues in social status were measured.

Table 1. Reliability coefficients of scales and questionnaires

\begin{tabular}{|c|c|c|}
\hline Coefficient of reliability & Dimension & Variables \\
\hline 0.72 & --- & Self-esteem \\
\hline 0.75 & --- & Satisfaction \\
\hline 0.72 & Spirituality to God & \multirow{2}{*}{ Spirituality } \\
\hline 0.76 & Spirituality to existence & \\
\hline 0.74 & Faith dimension & \multirow{3}{*}{ Religious } \\
\hline 0.74 & Affection dimension & \\
\hline 0.84 & Sequence dimention & \\
\hline 0.78 & --- & Hope \\
\hline 0.85 & --- & Economic conditions \\
\hline 0.79 & $\begin{array}{ll}-- \\
--\end{array}$ & Total Inventory \\
\hline
\end{tabular}

As you see all the questions of questionnaire had high reliability above $0 / 70$, which indicates the degree of validity and reliability of the questionnaire.

Investigate the structural model (path analysis) of study 


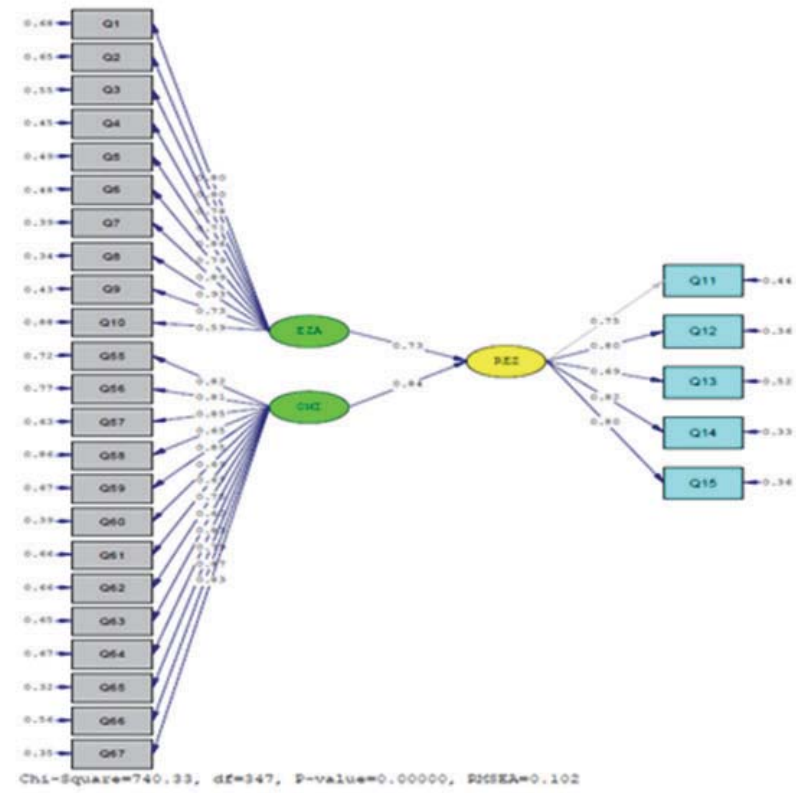

Figure 1. significant model ofthe main hypothesis of researchin estimating the standard

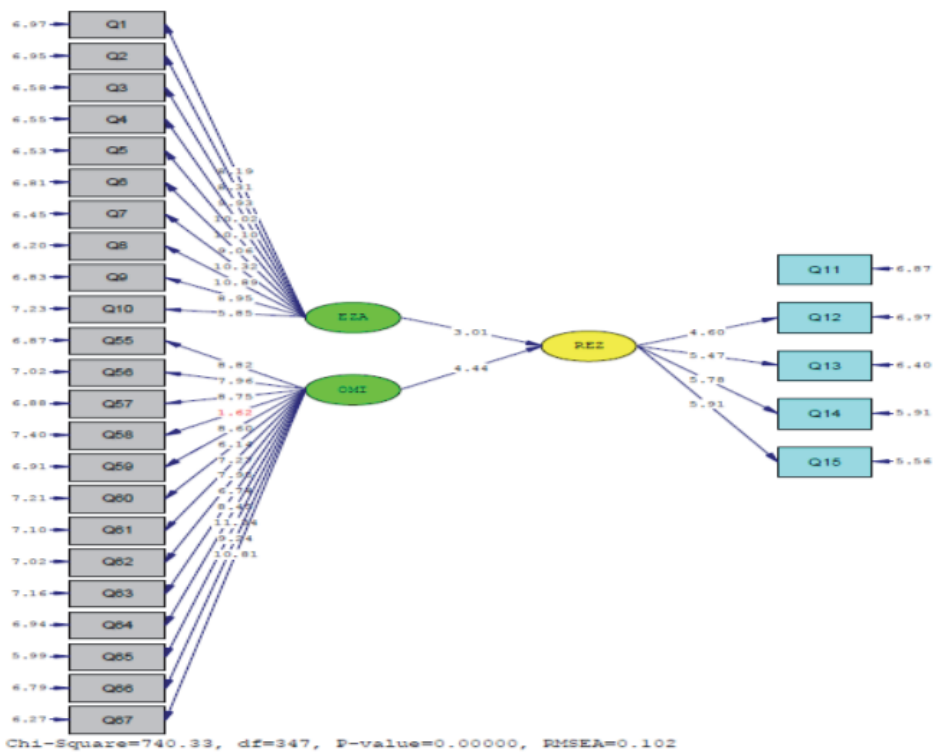

Figure 2. significant model of the main hypothesis of research in meaning coefficient status

Table 2. the result of structure equation model analysis

First main hypotheses

\begin{tabular}{ccccc}
\hline Result of test & T-value & Standard coefficent & dependent variable & Independent variable \\
\hline $\mathrm{H}_{0}$ & 4.44 & 0.84 & Satisfaction & hope \\
\hline
\end{tabular}


Table 3. the result of structure equation model analysis

Second main hypotheses

\begin{tabular}{ccccc}
\hline Result of test & T-value & Standard coefficent & dependent variable & Independent variable \\
\hline $\mathrm{H}_{0}$ & 3.01 & 0.73 & Satisfaction & Self-esteem \\
\hline
\end{tabular}

Table 4. the result of structure equation model analysis

\begin{tabular}{ccccc}
\hline Result of test & T-value & Standard coefficent & dependent variable & Independent variable \\
\hline $\mathrm{H}_{0}$ & 6.99 & 0.68 & Satisfaction & Spirituality \\
\hline $\mathrm{H}_{0}$ & 7.66 & 0.77 & hope & Spirituality \\
\hline $\mathrm{H}_{0}$ & 8.47 & 0.79 & Satisfaction & hope \\
\hline $\mathrm{H}_{0}$ & 8.24 & 0.73 & Self-esteem & Spirituality \\
\hline $\mathrm{H}_{0}$ & 8.89 & 0.75 & Satisfaction & Self-esteem \\
\hline
\end{tabular}

The result of structure equation model analysis

\begin{tabular}{ccccc}
\hline Result of test & T-value & Standard coefficent & dependent variable & Independent variable \\
\hline $\mathrm{H}_{0}$ & 7.33 & 0.78 & Satisfaction & Religious \\
\hline $\mathrm{H}_{0}$ & 7.64 & 0.7 & hope & Religious \\
\hline $\mathrm{H}_{0}$ & 8.47 & 0.79 & Satisfaction & hope \\
\hline $\mathrm{H}_{0}$ & 7.58 & 0.63 & Self-esteem & Religious \\
\hline $\mathrm{H}_{0}$ & 8.89 & 0.75 & Satisfaction & Self-esteem \\
\hline
\end{tabular}

Table 5. comparison of indexes on model with allowed amount

\begin{tabular}{cccll}
\hline Result & Model 2 & Model 1 & allowed amount & indexes \\
\hline Good & 0.93 & 0.91 & Above 0.9 & GFI \\
\hline Good & 0.95 & 0.94 & Above 0.9 & AGFI \\
\hline Good & 0.10 & 0.12 & Around zero & RMR \\
\hline Good & 0.092 & 0.092 & Around zero & SRMR \\
\hline Good & 0.90 & 0.94 & Above 0.9 & NFI \\
\hline Good & 0.93 & 0.96 & Above 0.9 & $\mathrm{IFI}$ \\
\hline Lower than limit & 0.00 & 0.00 & $0.01 \leq \mathrm{p} . \leq 0.05$ & $\mathrm{p}$ \\
\hline
\end{tabular}

\begin{tabular}{ccccc}
\hline Result of test & T-value & Standard coefficent & dependent variable & Independent variable \\
\hline $\mathrm{H}_{0}$ & 8.20 & 0.80 & Satisfaction & Socio-economic conditions \\
\hline $\mathrm{H}_{0}$ & 7.28 & 0.66 & hope & Socio-economic conditions \\
\hline $\mathrm{H}_{0}$ & 8.47 & 0.79 & Satisfaction & hope \\
\hline $\mathrm{H}_{0}$ & 8.14 & 0.74 & Self-esteem & Socio-economic conditions \\
\hline $\mathrm{H}_{0}$ & 8.89 & 0.75 & Satisfaction & Self-esteem \\
\hline
\end{tabular}

\section{Discussion and Conclusions}

First hypothesis: the hope has a significant direct relationship between life satisfactions.

Since the coefficient standard of the two variables, hope and satisfaction equals to 0/84 and according to the amount of obtained T (4.44) is greater than 1/96 it can claim with0/95 percent confidence between hope and satisfaction there is meaningful relationship.

Considering that people with higher levels of hope see obstacles as a challenge and find another waysand apply their motivation in the new route. with regard to the business successes when facing obstacles, people go forward with positive emotions, in other words hopefulness to the future and living among Azad University students of Tehran lead to stay away from boredom and this causes the feeling of pleasure and satisfaction in their lives; in other words search and find solutions to get rid of the pressures and problems, put much energy in order to achieve the objectives which are assigned before attention and concern toward health the use of past experience to help the individual to feel more satisfaction to life. 
Sink (1999) examined the relationship between religiosity, spirituality and life satisfaction among college students and adults, and thus found that religiosity and spirituality with mental well-being and life satisfaction has meaningful relationship. In this study it was found that between gender, age, income and life satisfaction there is very weak relationship .

The results of Shogrin et al (2006) that hope, optimism, source of control and self-following were significantly correlated andalso hope and optimism were strong predictors in life satisfaction. The final structural model of this study are presented below, as well as the results of research Zoellick et al (2006), matches the Bailey (2007) result.

Second hypothesis: There is a significant relationship between self-esteem and life satisfaction.

Since the standard coefficient of twoself-esteemvariables and satisfaction is 0/84 and according to the obtained tvalue (3/01)is greater than 1/96 it can claim with 0/95 percent confidence between self-esteem and satisfaction there is meaningful relationship.

Self-esteem as a shield and protection act against psychological incompatibility and facilitate positive evaluation of life satisfaction, in other words having self-esteem among college Azad university students of Tehran cause the individual do not compare his life with others, not to blame himself respect himself and have confidence in his abilities, thesefeelings lead to sense of pleasure and satisfaction in their lives. The results of Sink (1999), Zoellick et al (2006), Jane (2001), Ayash - Abdo results and Alamoen (2007) showed that students' subjective well-being, has apositive significant correlation with self-esteem, optimism, and positive affect. The results showed that the internal structures of personality in relation to demographic variables are better predictors of life satisfaction.alsothe results of, Zhang and Ling (2012), Orphan (2003), Chen et al (2006), Yvlman and Tatar (2011) matches each other's results.

Third Hypothesis: according to the role ofmediatinghope, spirituality with life satisfaction has significant relations.

Due to higher T-value than 1/96 and also the greater 0/5 standard coefficientit can claim that betweenspirituality with life satisfaction there is meaningful relation. And hope has a roll of mediator.

Spirituality involves attitudes that based on beliefs about relation with itself, contact withothers, the world around, and finally with God and spirituality will increase life satisfaction.

The Perroneet al (2006)research studiesthe relationship of spirituality, family roles and life satisfaction among a group of keen adults. Results indicated that religious well-being and existential well-being and marital satisfaction havea significant role in their life satisfaction.

The exictance of direct and positive spirituality on satisfaction also observed in research results as Sink (1999), Zoellick et al (2006), Henderson (2002), Fu (2008) .

Fourth Hypothesis: The role of mediating hope, religiosity and life satisfaction has significant relations.

Due to higher T-value than 1/96 and also the greater $0 / 5$ standard coefficient it can claim that between religiosity with life satisfaction there is meaningful relation. And hope has a roll of mediator.

Religiosity and spirituality in general, are important factors in people lives of around the world. Campbell and colleagues (1979) found that religionis better and exact predictorthan secular and external factors inmental well-being .

In other words, attention to spiritual issues, thanksgiving to his divine blessings, hopeful to God's help and mercythe feeling of God's presence would increase the individual's satisfaction with life. Also according to the obtained scores, attention to religiosityincreasehope the result of Davis research (2006) showed that betweenreligiosity, hope and psychological disorders there is a significant relationship. Alsobetween hope and optimism and intrinsic religious orientation there is asignificant relationship the existence of direct and positive impact of religiosity on satisfaction in the results of, researchers such as Sink (1999), Zoellick et al (2006), Frynch and Joseph (1999), Vitale (2001), Balstrvs (2004) proved. The impact of religiosity on hope in researchers result of Sink(1999), Zoellick et al (2006), Davis (2006) also exist. relations.

Hypothesis V: considering the role of mediating hope, socio-economic status and life satisfaction has significant

Due to high T-value than $1 / 96$ andalso the greater standard coefficient than $0 / 5$ can be claimed that between socioeconomic statuswith satisfaction in life there is meaningful relation and hope has a mediatorroll .

In other words, the appropriate socio-economic status, lack of concern about the debt, the mortgage bank and having proper social positionlead to increase individual's satisfaction of life. Chen and colleagues (2006) in a sample of Chinese students realized that self-esteem is strong a predictorof life in social welfare, the existence of direct and positive impact of socio-economic status on satisfaction on the results of researchers like sink (1999), Zoellick et al. (2006), also was seen. relations.

Hypothesis Vl: according to the role of mediatingself-esteem, spirituality and life satisfaction has significant 
Due to high T-value than $1 / 96$ and the greater standard coefficient than $0 / 5$ can be claimed that between spirituality and life satisfaction there is ameaningful relationship and self-esteem has a roll of mediator.The ultimate source of our life is spiritualityand gives it meaning and purpose. Spirituality for meaning and purpose which gives to our lives creates a deep passion and enthusiasm in all of us.In other words, attention to spiritual issues, thanksgiving to his divine blessings, hopeful to God's help and mercy the feeling of God's presence would increase the individual's satisfaction with life.Kamya (2000) in her research on students realized that between spiritual welfare and self-esteem there is positive relationship in a way people with high levels of welfare have reported higher self-esteem. Also, between spiritual well-being and neuroticism there is meaningful relationship.Results showed that spiritual well-being is a strong predictor of self-esteem the existence of spirituality impact on self-esteem proved the results of such researchers, Hyman (2007), Fu (2008), Singh (1999), Zoellick et al (2006).

Hypothesis VII: according to the role of mediating self-esteem, spirituality and life satisfaction has significant relations.

Due to high T-value than 1/96 and the greater standard coefficient than 0/5 can be claimed that spirituality and life satisfaction has a meaningful relationship and self-esteem has a roll of mediator.

Having a meaning and purpose in life, the sense of having to sublime reference, hopeful to God's help during hard condition of life, having social protection and the like are such resources that people through its benefit while facing stressful incidents tolerate less damage and because of the personal and social awareness of religion bring a kind of satisfaction of life. Zoligeand colleagues (2006) examined the relationship between spirituality, religiousness and life satisfaction among college students,in this study the perceived health had an intervening or mediating variable. The results showed that the model of spirituality and life satisfaction through self-perceived health is quite fitted. Religiosity model and life satisfaction through self-perceived health was relatively good. Both men and women were similar. Students who attained higher scores also scored higher in self-perceived health scale and this effect on life satisfaction. The impact of religiosity on self-esteem on the results of researchers such as Ball et al (2003), Sink (1999) has beenproved.

The eighth hypothesis: according to the role of mediating self-esteem, socio-economic status has significant relations with life satisfaction.

Due to high T-value than $1 / 96$ and the greater standard coefficient than $0 / 5$ can be claimed that socio-economic status and life satisfaction have a meaningful relationship and self-esteem has a roll of mediator. In other words, the appropriate socio-economic status, lack of concern about the debt, the mortgage bank, having proper position lead to increase individual's consent. Chen et al (2006) in a sample of Chinese students found that self-esteem is a strong predictor of, well-being and satisfaction in life.

The positive and direct impact of socio-economic status on satisfaction observed in the results of researchers such as Sink (1999), Zoellick et al (2006).

\section{References}

Ryan, R. M., \&Deci, E. L. (2001). On happiness and human potentials:A review of research on hedonic and eudaimonic wellbeing.Annual Review of Psychology, 52, 141-166

Diener, E. (2009). Assessing Well-Being, Springer DordrechtHeidelberg London New York

Lent, R.W. ( 2004). Toward a unifying and practical perspective onwell-being and psychosocial adjustment, Journal of CounselingPsychology 51, 482-509.

McFadden, S. H. (1995). Religion and well-being in ageing persons inan ageing society. Journal of Social Issues, 51, 161-175.

Zheng, X., Sang, D., \& Lin, Q. (2004). Personality, cognitive and socialorientations and subjective wellbeing among Chinese students.Australian Psychologist, 39, 166-171

Scheier, M. F., \& Carver, C. S. (2002).Optimism. In C. R. Snyder andS. J. Lopez(Eds.), Handbook of positive psychology (pp. 231243).New York: Oxford University Press.

Shogren, K., A. Lopez., S. J. Wehmeyed, M, L. Little., T, D., \&Pressgrove, C. L. (2006). The role of Positive Psychology constructs in predicting life satisfaction in adolescents with and without cognitive disabilities: exploratory study. The journal ofpositive psychology. 1(1):37-59

Zhang, L., W. (2005). Prediction of Chinese life satisfaction:Contribution of collective self-esteem. International Journal ofPsychology, 40 (3), $189-200$

Poloma, M., M., \&Pendelton, B. F. (1990).Religious domains andgeneral well-being.Social Indicators Research, 22, 255-276.

Rosenberg, R. M. (1965). Society and the adolescent self-image.Princeton, NJ: University Press. 